\title{
Gold Nanoplates as Cancer-Targeted Photothermal Actuators for Drug Delivery and Triggered Release
}

\author{
Tyler Brann, ${ }^{1}$ Dhruvinkumar Patel, ${ }^{1}$ Rajat Chauhan, ${ }^{1}$ Kurtis T. James, ${ }^{1}$ Paula J. Bates, ${ }^{2}$ \\ Mohammad Tariq Malik, ${ }^{2}$ Robert S. Keynton, ${ }^{1}$ and Martin G. O'Toole ${ }^{1}$ \\ ${ }^{1}$ Department of Bioengineering, University of Louisville, Louisville, KY 40208, USA \\ ${ }^{2}$ Department of Medicine and James Graham Brown Cancer Center, University of Louisville, Louisville, KY 40202, USA
}

Correspondence should be addressed to Martin G. O’Toole; mgotoo03@louisville.edu

Received 22 January 2016; Revised 24 March 2016; Accepted 29 March 2016

Academic Editor: Gang Liu

Copyright (C) 2016 Tyler Brann et al. This is an open access article distributed under the Creative Commons Attribution License, which permits unrestricted use, distribution, and reproduction in any medium, provided the original work is properly cited.

\begin{abstract}
The selective exposure of cancerous tissue to systemically delivered chemotherapeutic agents remains a major challenge facing cancer therapy. To address this question, a near infrared responsive oligonucleotide-coated (AS1411, hairpin, or both) gold nanoplate loaded with doxorubicin is demonstrated to be nontoxic to cells without triggered release, while being acutely toxic to cells after 5 minutes of laser exposure to trigger DOX release. Conjugation of oligonucleotides to the nanoplates is confirmed by an average increase in hydrodynamic diameter of $30.6 \mathrm{~nm}$, an average blue shift of the plasmon resonance peak by $36 \mathrm{~nm}$, and an average $-10 \mathrm{mV}$ shift in zeta potential of the particles. DOX loading through intercalation into the hairpin DNA structure is confirmed through fluorescence measurements. For both GNP-Hairpin and GNP-Hairpin-AS1411, $\sim 60 \%$ of loaded DOX is released after the first 5 minutes of laser exposure $(\lambda=817 \mathrm{~nm})$, with complete release after two more 5-minute exposures. Preliminary proof of concept is demonstrated in vitro using A549 and MDA-MB-231 cell lines as models for breast and lung cancer, respectively. Exposure of cells to untriggered DOX-loaded conjugate with no laser exposure results in little to no toxicity, while laser-triggered release of DOX causes significant cell death.
\end{abstract}

\section{Introduction}

Gold nanoparticles have been studied for many years, due to their unique optical and physical characteristics, with the vast majority of research being done with gold nanospheres, the most common and easily produced particle type $[1,2]$. More recently research has been done on more complex geometries of gold nanoparticles, such as triangular nanoplates, which exhibit similar overall characteristics as gold nanospheres but with additional useful features, such as high absorbance in the near infrared (nIR) region of the electromagnetic spectrum [3-8]. Due to high transmissivity of nIR light through biological media [9], this property has proved invaluable for targeted photothermal ablation of living tissue with minimal collateral damage when targeting cancer cells $[10,11]$. With the ability to reproducibly synthesize a large batch of gold nanoplates [12] with tunable properties, using a technique such as Diasynth [13], the unique therapeutic possibilities of these particles can be explored.

Conjugation of gold nanoplates (GNPs) with various macromolecules has been studied for the ability to provide stability as well as drug delivery options to create versatile platforms for biological applications [14]. One such class of biomolecule, oligonucleotides, has become popular for this application in recent years $[1,15,16]$. The application of DNA/RNA strands to create tertiary structures such as stem loops, or hairpins, has also been used independently to create biologically compatible drug delivery platforms through intercalation of therapeutic agents [17]. These drugs were then released through thermal, chemical, or enzymatic denaturation of the DNA. Still other sequences of single stranded DNA, such as the guanosine-rich aptamer AS1411, have been found to have direct therapeutic effects against cancer cells $[18,19]$. The method of action of AS1411 has been 
through geometric recognition of nucleolin, a nuclear protein displayed on the cell surface of most cancer cells [20]. AS1411 has been effectively internalized into cancer cells through a process involving macropinocytosis and was retained in the cell cytoplasm. Any uptake of AS1411 in nonmalignant cells appeared to be through standard internalization processes such as endocytosis, upon which the AS1411 was released from the cells, thus making AS1411 effectively inert to noncancerous cells.

Research into oligonucleotide-functionalized GNPs has been broad with applications ranging from creating higher order supramolecular structures, selective binding of aptamers to cells, or use as diagnostic markers for biosensing [14, 21]. Each has shown some success as a tool for cancer diagnostics and therapy but not without limitations. For example, conjugation of oligonucleotides that possess a propensity to form a hairpin structure to the surface of a gold nanoparticle, thermal denaturation, and loss of the hairpin secondary structure has been achieved by heating the gold via the application of external light to induce localized surface plasmon resonance [22]. Furthermore, DNA-functionalization of GNPs, intercalation of doxorubicin (DOX) into hairpin DNA, and photothermal release using focused laser light have been accomplished using small spherical GNPs and visible range light [22]. These approaches, however, suffered from long activation times (>30 min) and a wavelength of light with poor tissue penetration. Thus, there is a need for a single complex that combines photothermal drug release with nIR light together with the cancer-targeting ability of AS1411, which has the potential to bring a multifaceted approach to cancer therapy.

\section{Materials and Methods}

2.1. Instrumentation. All absorbance spectra were measured on a Varian (Palo Alto, CA) Cary 50 Bio UV-Vis Spectrophotometer using $12 \mathrm{~mm}$ quartz cuvettes with samples at a $10 \mathrm{x}$ dilution in nanopure water, unless otherwise stated. Zeta potential and particle sizes (dynamic light scattering (DLS)) were measured using a Malvern Instruments (Worcestershire, United Kingdom) Zetasizer Nano ZS90, at a 10x dilution unless otherwise stated. Fluorescence was measured with a Turner Biosystems (Promega, Madison, WI) Modulus Fluorometer using the green fluorescence module accessory $\left(\lambda_{\mathrm{Ex}}=460 \mathrm{~nm}, \lambda_{\mathrm{Em}}=515-570 \mathrm{~nm}\right)$ and glass microcell cuvettes with all readings being undiluted unless noted. Centrifugation was performed using a Beckman Coulter (Brea, CA) Microfuge 16. Sonication was performed with a Misonix (Farmingdale, NY) Microson XL 2000 sonication probe. The laser used for heating of the particles was a Coherent Inc. (Santa Clara, CA) FAP System Model with a fixed emission wavelength of $817 \mathrm{~nm}$ and variable power setting. Actual laser power was measured before lasering using a Coherent FieldMax II-TO. Solution temperature while lasering was measured using an Omega Engineering (Stamford, CT) Thermocouple Data Logger (OM-EL-USBTC-USB) and Omegasoft Data Logger Software (Rev. 6.8) using a type $\mathrm{K}$ thermocouple. Cellulose Acetate Dialysis tubing (43 mm wide; $12 \mathrm{kDa}$ molecular weight cutoff) was purchased from Sigma-Aldrich (St. Louis, MO) and stored in DI water in a refrigerator at $4^{\circ} \mathrm{C}$. Illustra NAP-25 columns were purchased from General Electric Healthcare (Buckinghamshire, United Kingdom).

2.2. Reagents and Reactants. Hydrogen tetrachloroaurate-III trihydrate $\left(\mathrm{HAuCl}_{4} * 3 \mathrm{H}_{2} \mathrm{O}\right)$ was purchased from Alfa Aesar (Ward Hill, MA 01835). Sodium thiosulfate pentahydrate, phosphate buffer tablets, dithiothreitol (DTT) at $1 \mathrm{M}$ concentration in $\mathrm{H}_{2} \mathrm{O}$, and dry powder doxorubicin hydrochloride were purchased from Sigma-Aldrich (St. Louis, MI 63103). A549 adenocarcinomic human alveolar basal epithelial cells and MDA-MB-231 breast cancer epithelial cell lines were purchased from ATCC (American Type Culture Collection, Manassas, VA). Dulbecco's modified Eagle's media (DMEM), $10 \%$ FBS, and 1\% Penicillin-Streptomycin were purchased from Thermo Fisher Scientific (Carlsbad, CA). Live Dead assay kits were purchased from Life Technologies (Life Technologies, Grand Island, NY). Oligonucleotides were purchased from Integrated DNA Technologies (Coralville, IA) and dissolved in nanopure water to create stock solutions between 10 and $1 \mu \mathrm{M}$. See Table 1 for oligonucleotide specifications.

2.3. Particle Design. The particle system consists of a triangular gold nanoplate with a coating of thiolated, hairpinforming oligonucleotides and/or thiolated AS1411. The hairpin structures are then loaded with doxorubicin (DOX), which intercalates into the hairpin structure, Figure 1. Upon exposure to focused near infrared energy, the particles heat up and denature the hairpin sequences, which releases the DOX.

2.4. Gold Nanoplate Synthesis. Gold nanoplates were synthesized using the Diasynth process with reaction parameters chosen to yield particles with maximum absorbance at approximately $820 \mathrm{~nm}$ to match the coherence laser wavelength $[12,13] .32 .6 \mathrm{~mL}$ of $1.76 \mathrm{mM}$ gold salt solution was added to a $12 \mathrm{~cm}$ section of dialysis tubing followed by quickly adding $7.4 \mathrm{~mL}$ of $3 \mathrm{mM}$ sodium thiosulfate solution and agitated for 5 seconds. The membrane was then clipped and submerged in a circulated bath of DI water $(\geq 25 \mathrm{~L})$ maintained at $27^{\circ} \mathrm{C}$ by a Thermo (Waltham, MA) NESLAB RTE-221 Circulator. After reacting for 1 hour the membrane was removed and the solution was emptied into a $40 \mathrm{~mL}$ plastic tube.

2.5. Oligonucleotide Preparation. Solutions of $7.7 \mu \mathrm{M}$ AS1411 and $5 \mu \mathrm{M}$ hairpin were created in nanopure water. Each oligonucleotide solution was stored at $4^{\circ} \mathrm{C}$ with the thiol modification containing a disulfide bond. The DNA was titrated to $0.18 \mathrm{M}$ sodium phosphate buffer $(\mathrm{PB})(\mathrm{pH} 8)$, heated to $90^{\circ} \mathrm{C}$, and then allowed to cool. Next the DNA solutions were shaken in $0.1 \mathrm{M}$ DTT for at least 1 hour and then run through Illustra NAP-25 columns using $10 \mathrm{mM}$ phosphate buffer (PB) ( $\mathrm{pH}$ 8.0) as the eluent. Each sample of oligonucleotide was then analyzed with UV-Vis spectroscopy for the absorbance at $260 \mathrm{~nm}$ to determine final DNA concentration. 
TABLE 1: Oligonucleotide specifications.

\begin{tabular}{|c|c|c|c|c|}
\hline DNA & Modifiers & Conformation & Melting temperature $\left({ }^{\circ} \mathrm{C}\right)$ & $\begin{array}{l}\text { Extinction coefficient at } \\
260 \mathrm{~nm}\left(\mathrm{~L} \cdot \mathrm{mol}^{-1} \cdot \mathrm{cm}^{-1}\right)\end{array}$ \\
\hline Hairpin & $3^{\prime}$ Thiol & Hairpin/stem loop & 69.7 & 453,600 \\
\hline \multicolumn{5}{|c|}{ Sequence: $5^{\prime}$-AGC TAG CGC TAG CGC TAG CTT TTG CTA CGC CTA GCG CTA GCT TTT TTT TTT /3ThiolMC3-D/-3' } \\
\hline AS1411 & $5^{\prime}$ Thiol & Quadruplex (dynamic) & 67.0 & 298,000 \\
\hline \multicolumn{5}{|c|}{ Sequence: $5^{\prime}$-/5ThiolMC6-D/TTT TTT GGT GGT GGT GGT TGT GGT GGT GGT GG-3' } \\
\hline
\end{tabular}

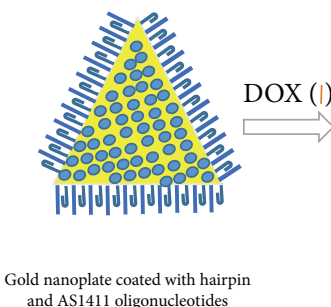

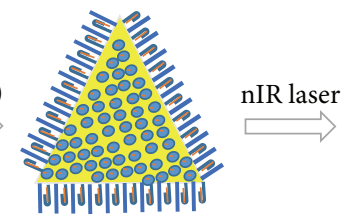

Doxorubicin loaded gold nanoplate

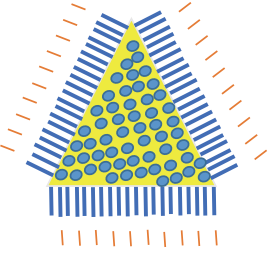

Doxorubicin release through DNA denaturation

FIGURE 1: Representation of the mechanism of the oligonucleotide-coated gold nanoplate as a photothermal drug release vehicle.

2.6. Functionalization of Gold Nanoplates with DNA. Appropriate volumes of gold nanoplates and oligonucleotides (both hairpin and AS1411 sequences, vide infra) samples were incubated at $4^{\circ} \mathrm{C}$ and vortexed every thirty minutes for the first four hours and then further incubated at $4^{\circ} \mathrm{C}$ overnight. On the next day, the excess DNA was removed through serial centrifugations ( $2500 \times \mathrm{g}$ for 4 minutes) and washings. The resulting pellet was resuspended in $5 \mathrm{mM}$ PB solution between washings. The sample was then sonicated 10 times in 1-second bursts and vortexed to fully resuspend all particles. This centrifugation, supernatant removal, and resuspension were performed three times for each sample. After this stage each sample and corresponding supernatant were analyzed by UV-Vis spectroscopy, DLS, and zeta potential measurement. For cell studies, oligonucleotide-coated gold nanoplate solutions were slowly graduated to physiological salt concentrations through the slow addition of $1 \mathrm{M}$ phosphate buffered saline (PBS) solutions in $100 \mu \mathrm{L}$ increments every 2 to 4 hours over a 2 -day period.

2.7. Loading Doxorubicin into Hairpin. A $100 \mu \mathrm{M}$ stock solution of doxorubicin hydrochloride (DOX) in nanopure water was diluted to $10 \mu \mathrm{M}$ before addition to GNP-oligonucleotide particle solutions. This solution was added to gold nanoplates at a $3 \mathrm{OD}$ concentration to achieve a final DOX concentration of $0.5 \mu \mathrm{M}$. These samples were allowed to react for 2 hours at room temperature. To remove excess DOX the samples were centrifuged and washed 3 times at $1000 \times \mathrm{g}$ for 4 minutes. The resulting pellet was resuspended in $5 \mathrm{mM}$ PB solution between washings. These samples were then analyzed for UVVis spectra for particle content and absorbance at $817 \mathrm{~nm}$ and found to be suitable for laser release and cell experiments.

2.8. Laser-Induced Release of Doxorubicin. Using the nIR absorbance peak obtained from the UV-Vis spectrum of DOX-loaded particles, the samples were diluted to $0.5 \mathrm{OD}$ and a volume of $0.5 \mathrm{~mL}$ using nanopure water. Before laser application, each sample was then analyzed for fluorescence along with a control that was not loaded with DOX, from the same batch of functionalized particles of similar dilution. A fluorescence measurement $\left(\lambda_{\mathrm{Ex}}=460 \mathrm{~nm} ; \lambda_{\mathrm{Em}}=515-\right.$ $570 \mathrm{~nm}$ ) was taken 3 times for each sample. In turn, each sample was dispensed into a 48 -well plate and heated with a laser. The $817 \mathrm{~nm}$ wavelength laser was set to $8200 \mathrm{~mA}$ $(1000 \mathrm{~mW})$ and emitted $21 \mathrm{~cm}$ above the target. The laser area consisted of a circle with a diameter of $1.25 \mathrm{~cm}$ that fully covered the sample well. The actual laser power at the well plate was measured with a Coherent Laser Power Meter as approximately $800 \mathrm{~mW} / \mathrm{cm}^{2}$, with the temperature being measured with an Omega thermocouple probe and USB data logging device. The duration of the laser application was 5 minutes, followed by immediate collection and centrifugation of the sample at $1000 \times \mathrm{g}$ for 2 to 4 minutes. The supernatant was collected and the pellet resuspended to $0.5 \mathrm{~mL}$ with nanopure water and vortexed briefly. This process was performed 3 times to obtain a release profile of DOX. After the final centrifugation and supernatant collection, the 3 collected supernatants were centrifuged at $1000 \times \mathrm{g}$ for 4 minutes to pellet any coincident gold still in solution. Subsequently, $200 \mathrm{uL}$ from the top of each supernatant was analyzed for fluorescence, with a total of 3 measurements per sample. This procedure was done for 3 replicates of DOXloaded and control samples of GNPs with hairpin only and GNPs with hairpin and AS1411.

2.9. Cell Culture and Lasering. A549 adenocarcinomic human alveolar basal epithelial cells and MDA-MB-231 breast cancer epithelial cells were cultured in DMEM with $10 \%$ FBS and $1 \%$ Penicillin-Streptomycin in a $37^{\circ} \mathrm{C}$ incubator with $5 \% \mathrm{CO}_{2}$. For lasering experiments, cells were seeded in 12 -well plates at 10000 cells $/ \mathrm{mL}$. Cell culture media were then removed from the cells and replaced by cell culture media containing the appropriate amount of oligonucleotidecoated gold nanoplate with or without DOX. Cells were 
TABLE 2: Size and zeta potential of oligonucleotide-functionalized GNPs.

\begin{tabular}{|c|c|c|c|c|c|c|}
\hline & \multicolumn{3}{|c|}{ Particle size (nm) } & \multicolumn{3}{|c|}{ Zeta potential $(\mathrm{mV})$} \\
\hline & Bare & DNA-coated & Change & Bare & DNA-coated & Change \\
\hline GNP-Hairpin average (standard deviation) & $69.11(2.23)$ & $92.61(9.83)$ & $23.50(7.68)$ & $-31.25(0.78)$ & $-43.15(1.69)$ & $-11.90(2.47)$ \\
\hline GNP-AS1411 average (standard deviation) & $67.81(2.24)$ & $110.04(21.74)$ & $42.23(23.92)$ & $-31.70(0.78)$ & $-43.10(3.10)$ & $-11.40(2.52)$ \\
\hline GNP-Hairpin-AS1411 average (standard deviation) & $67.81(2.24)$ & $93.95(5.69)$ & $26.13(5.87)$ & $-31.70(0.78)$ & $-41.22(0.65)$ & $-9.52(0.58)$ \\
\hline
\end{tabular}

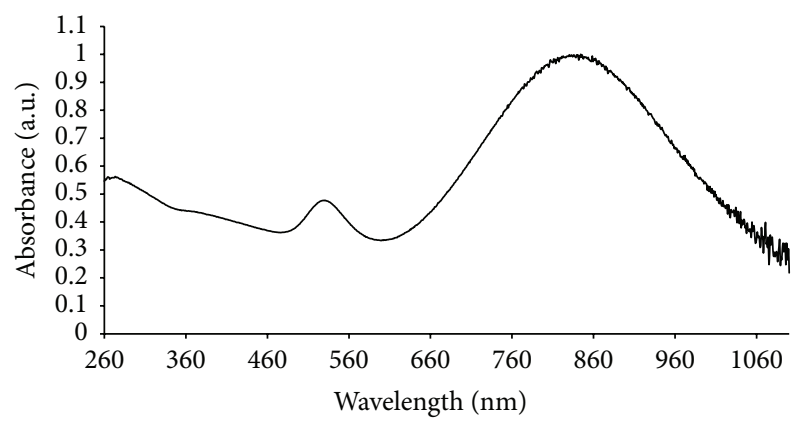

FIGURE 2: UV-Vis spectrum of representative gold nanoparticles synthesized using the Diasynth method. The two peaks approximate the ratio of spheres and plates. Absorbance in therapeutic windows indicates suitability for laser absorption.

lasered after $24 \mathrm{hrs}$ ( $80 \%$ confluency). Laser experiments were performed under the same conditions as for the DOX release studies above. After lasering, cells were washed thoroughly with PBS followed by performing a Live/Dead fluorescence assay according to the manufacturer instructions, and the cells were visualized and photographed on an Accuscope epifluorescence microscope.

2.10. Statistical Analysis. All studies were performed in at least triplicate, unless otherwise noted. Statistical analysis was conducted in Minitab Software (Minitab, State College, PA). Statistical significance was considered when $p<0.05$. All data has been presented as an average with standard deviation as error bars.

\section{Results and Discussion}

3.1. Gold Nanoplates Synthesis. Near infrared absorbing GNPs are produced using the Diasynth method and are expected to contain a large fraction of nanoplates, comparatively few spheres, and with a controllable surface plasmon resonance (SPR) band within the NIR range [12, 13]. The spectrum of a typical sample used for subsequent functionalization, DOX loading, and lasering are presented in Figure 2. The UV-Vis absorbance spectrum shows favorable SPR bands that absorb light strongly within the desired optical therapeutic window and at the $817 \mathrm{~nm}$ wavelength of the available laser. Based on previous analysis of the Diasynth process, the ratio of the nIR peak to the peak at $530 \mathrm{~nm}$ suggests that $28-29 \%$ of the sample is composed of gold nanoplates [13]. The average size for the nanoplates, as measured by dynamic light scattering, is found to be $68.46 \pm 2.74 \mathrm{~nm}$. This size of nanoplate was chosen because the plasmon resonance peak is close to the operating wavelength $(817 \mathrm{~nm})$ of the nIR laser used in this study. This matching of plasmon resonance to laser wavelength will help to insure maximum photothermal efficiency of the samples. The average values for the zeta potential are $-31.48 \pm 0.95 \mathrm{mV}$.

3.2. Functionalization of GNPs with Oligonucleotides. Oligonucleotides are conjugated to the gold nanoplate surface via a thiol modification provided by the manufacturer. For every batch of oligocoated particles, the following samples are created: GNPs with hairpin (GNP-Hairpin), GNPs with AS1411 (GNP-AS1411), and GNPs with both hairpin and AS1411 (GNP-Hairpin-AS1411). The samples with both hairpin and AS1411 molecules are used in an equal molar ratio of each oligonucleotide and each are added simultaneously to the gold solution. The extinction coefficients of the oligonucleotides are provided by the supplier and although the precise parameter for the GNPs is not determined, gold nanoplate concentrations are based on studies showing spherical nanoparticles of silver and gold to have similar plasmon resonance extinction coefficients on the order of $10^{9}$ to $10^{10} \mathrm{~L} / \mathrm{mol}-\mathrm{cm}$ [23]. Ultimately, variation in this parameter only becomes a factor when looking at the exact loading efficiencies, since any ratio of nanoplates to oligonucleotides will acquire some degree of coating due to the reliability of the gold-thiol interaction. For this study, a ratio of 1120 oligonucleotides per gold nanoparticle is used to ensure sufficient loading of DNA. As shown in previous studies, as well as here, uncoated gold nanoplates are sensitive to aggregation from the exposure to salt [24]. The oligonucleotide solutions are at a $10 \mathrm{mM}$ sodium phosphate buffer concentration ( $\mathrm{pH} \mathrm{8.0)}$ when added to the gold solution and then further diluted to $5 \mathrm{mM}$ with the addition of nanopure water. Additionally, irreversible aggregation of the GNPs onto the walls of containers is also mitigated by the use of low DNA-binding tubes, such as LoBind Eppendorf (Hamburg, Germany) centrifuge tubes.

The success of coating the GNPs with DNA is confirmed through change in the size and zeta potential of the particles. As shown in Table 2, the size increases across all samples after reacting with the oligonucleotides. The average size increase is $23.5,42.23$, and $26.13 \mathrm{~nm}$ for the GNP-Hairpin, GNPAS1411, and GNP-Hairpin-AS1411, respectively, with GNPAS1411 having the highest standard deviation at $23.9 \mathrm{~nm}$. The zeta potential data are more consistent across samples with the average change in the potentials being $-11.90,-11.40$, and $-9.52 \mathrm{mV}$, respectively, with the highest standard deviation of $\pm 2.47 \mathrm{mV}$ occurring for GNP-Hairpin-AS1411. Analysis of variance indicates there is a significant difference in size between the bare and coated particles $(p<0.05)$, while the 


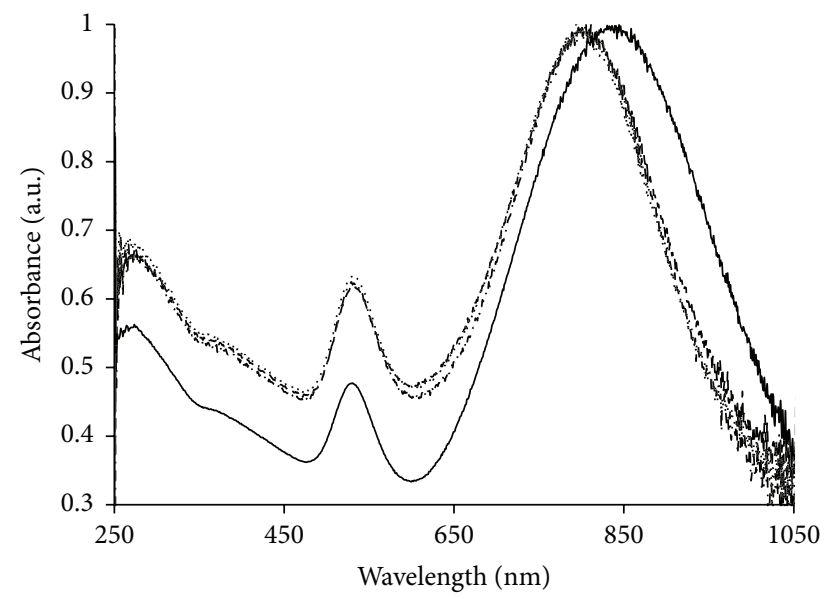

FIgURE 3: UV-Vis spectra of GNP-oligonucleotides (solid line: bare GNPs; short dashed line: 1:1 GNP-Hairpin-AS1411; long dashes: GNP-AS1411; compound short and long dashes: GNP-Hairpin).

type of coating, that is, hairpin, AS1411, and hairpin/AS1411, is not a significant factor.

The overall trend that indicates successful binding is the significant increase in size. This is anticipated since the physical size of the complex is increasing with the addition of the oligonucleotides onto the surface of the particle. Assuming a length of $0.33 \mathrm{~nm}$ per base, the single stranded hairpin and AS1411 would be $16.83 \mathrm{~nm}$ and $10.56 \mathrm{~nm}$, respectively [25]. After the hairpin and AS1411 fold into their respective structures of double strand and quadruplex, they become approximately $8.42 \mathrm{~nm}$ and $2.64 \mathrm{~nm}$. Binding of these structures onto each side of the nanoparticle subsequently increases the overall size by at least $16 \mathrm{~nm}$ and $5 \mathrm{~nm}$, respectively. Additionally, the DLS reading perceives the hydration sphere of the particle taking into account the interaction with water, thus increasing the apparent size of charged particles.

The UV-Vis spectra of the oligocoated GNP show a set of coated particles that maintain a high SPR peak in the nIR range, Figure 3. This is crucial to the success of the particles as a large shift away from the laser frequency or a loss in absorbance would reduce the efficacy of these particles to heat with $817 \mathrm{~nm}$ laser application. The main difference between this study and those previously reported using gold nanospheres is that gold nanospheres have shown greater stability to the addition of salt where gold nanoplates tend to aggregate $[22,26]$. This is attributed to the relatively large expanse of flat surface area on the plates, which contribute to more efficient electrostatic attraction between neighboring plates in solution, as well as larger amounts of oligonucleotides capable of interacting between plates [27, 28].

GNP-AS1411 and GNP-Hairpin particles were also characterized with STEM imaging, Figure 4. Both images reveal large populations of nanoplates with average edge lengths of $82.4 \pm 13.1 \mathrm{~nm}$ and thicknesses of $10.3 \pm 1.8 \mathrm{~nm}$. Also present are pseudooctahedral particles with diameters near $30 \mathrm{~nm}$ which have peak plasmon resonance absorption near $650 \mathrm{~nm}$ [29]. These pseudooctahedral particles are typical byproducts of the Diasynth process and have not been shown to affect the
TABLE 3: Size of aggregated oligofunctionalized GNPs.

\begin{tabular}{lcc}
\hline & \multicolumn{2}{c}{ Particle size (nm) } \\
& Bare & DNA-coated \\
\hline GNP-Hairpin & 86.16 & 407.65 \\
GNP-AS1411 & 86.16 & 354.75 \\
GNP-Hairpin-AS1411 & 86.16 & 340.75 \\
$\begin{array}{l}\text { GNP-DNA average (standard } \\
\text { deviation) }\end{array}$ & 86.16 & $367.72(35.28)$ \\
\hline
\end{tabular}

nanoplate plasmon resonance intensity in our samples, so no further attempts were made to remove them from the particle population.

For cell studies, it is necessary to increase the level of salt in the solutions so that they are isotonic with the cell culture media (typically $137 \mathrm{mM} \mathrm{NaCl}$ ). Care was taken to conduct this "salting in" of the particles to avoid aggregation. We were able to maintain well-dispersed particle suspensions after the salting in process, provided the salt addition was performed gradually over a two-week period. Particles were stable after this point with hydrodynamic diameters similar to unsalted particles in DI water (e.g., GNP-AS1411 was $110.4 \mathrm{~nm}$ before salting in and increased to $133.9 \mathrm{~nm}$ after). The zeta potential of the sample does decrease due to shielding of the particle charge by the counter ions in solution. For example, the zeta potential for GNP-AS1411 changed from -43.10 to -18.8 after salting in. The occurrence of aggregation from salt addition or other incidental processes causes a visible change in the solution from a dark purple to blue or gray with eventual colorlessness and gray or black large particulates settling and adhering to the tube surface. This aggregation occurrence can also be ascertained from DLS measurements, showing a size change from less than $100 \mathrm{~nm}$ to several hundred nanometers, as shown in Table 3, and loss of the nIR absorbance of the sample. Because of the propensity to aggregate, great care must be taken when raising the amount of salt in the GNPoligonucleotide solutions to physiological levels.

3.3. Loading Doxorubicin into Hairpin. After confirmation of DNA binding to the gold nanoplates the hairpin molecules are loaded with DOX for later release. DOX has been shown to intercalate between successive base pairs in double stranded DNA, with a preference for repeating C$G$ sequences [22]. Previous studies of DOX loading at a concentration of $5 \mu \mathrm{M}$ for a $300 \mathrm{nM}$ DNA hairpin show saturation of the hairpin at $4 \mathrm{DOX}$ molecules per hairpin [22]. Due to the decreased stability of the gold nanoplates in high salt concentrations, to which DOX contributes to its inherent charge, the concentration of doxorubicin used to load the particles is limited to $0.5 \mu \mathrm{M}$. This is not expected to provide saturation of the hairpin but will still allow for loading of the DOX and provide a measurable fluorescence upon release. For this step, only GNP-Hairpin and GNPHairpin-AS1411 are used as GNP-AS1411 should have little to no ability to intercalate with DOX, since it does not have repeating $\mathrm{C}-\mathrm{G}$ bases or traditional base pairing to provide the pi-stacking arrangements $[17,30]$. The analysis of the 


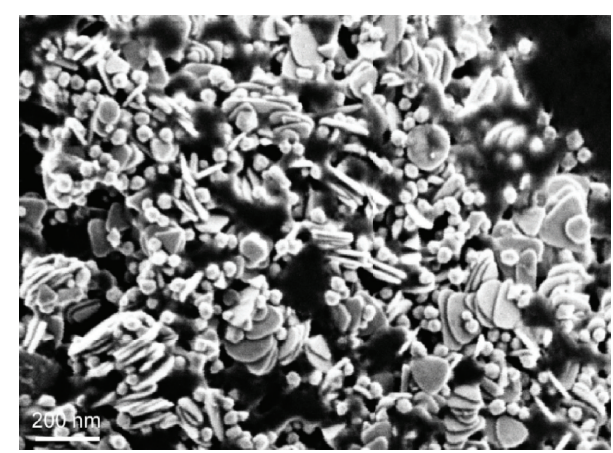

(a)

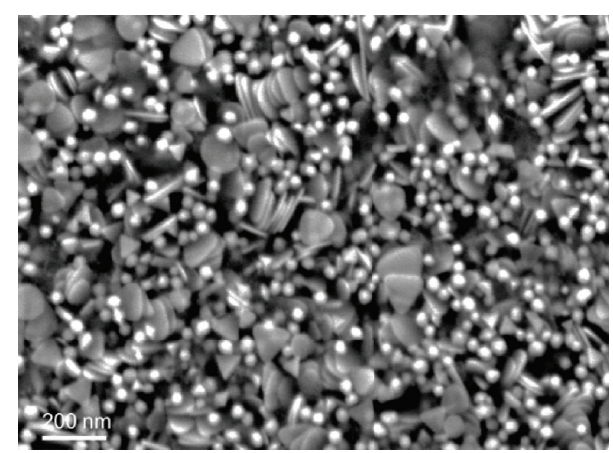

(b)

FIGURE 4: STEM images of GNP-AS1411 (a) and GNP-Hairpin (b). Both images were captured at $1 \mathrm{kV}$ EHT.

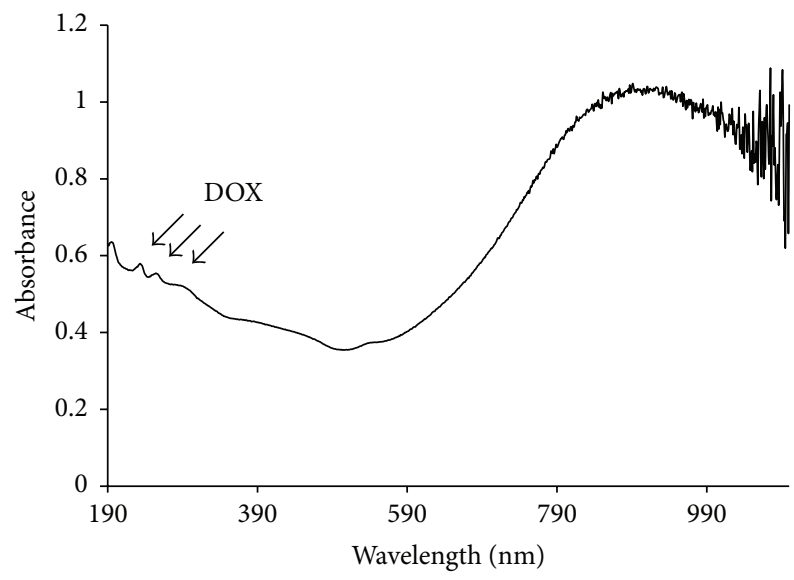

FIGURE 5: UV-Vis spectra of GNP-Hairpin loaded with DOX.

particles after loading and washing identifies a decrease in overall quality of the nIR peak, but not as severe as the case of aggregation. Additionally, during processing, the visible color of the particles remains constant and minimal adherence to the tube walls is observed. An optical spectrum of a GNPHairpin-DOX is shown in Figure 5. The presence of DOX in the sample is easily identified due to the 3 typical DOXrelated peaks in the $200-300 \mathrm{~nm}$ range [29].

DOX loading is quantified indirectly by measuring the fluorescence of the wash supernatants using the raw fluorescence measurements (see Table S1 in Supplementary Material available online at http://dx.doi.org/10.1155/2016/2036029) and a fluorescence calibration curve (Figure S1) for DOX. With an initial concentration of $0.5 \mu \mathrm{M}$ DOX being added during the loading of the particles, the DOX concentration in the supernatant is assumed to be the difference between the initial concentration and the loaded concentration. From this relationship, the amount of successfully loaded DOX can be calculated. The total number of nanoplates present in the volume of loaded particles can also be estimated from the spectral data, as mentioned previously. The number of DOX molecules and gold nanoplates in the final sample is used to find the number of DOX per nanoplate. Conservatively, assuming 1 molecule of DOX per hairpin molecule using our reduced amount of DOX, as Luo et al. found previously a saturation of 4 , the number of hairpins per gold nanoparticle can be calculated for GNP-Hairpin as $379.5 \pm 8.6$ and $380.8 \pm$ 8.9 for GNP-Hairpin-AS1411 [22].

These results indicate a reasonable number of oligonucleotides for the nanoplates, considering the indirect nature of the calculations. Because the GNP-Hairpin-AS1411 sample is reacted with half the quantity of hairpin one would expect a noticeable decrease in DOX loading capabilities; however, this is not observed. The difference between samples is relatively small, which potentially suggests that saturation conditions for the DOX with the hairpin coating are not reached. This is a reasonable assumption given the conservative amount of DOX added to the particle solutions in order to avoid particle aggregation. Inherent assumptions associated with this method for determining DNA loading include the estimated extinction coefficient of gold nanoplates, no fluorescence interference by gold nanoparticles, and sufficient washing in previous steps. The theoretical physical limit of DNA loading can be approximated using the surface area for a plate with an edge length of $70 \mathrm{~nm}$, thickness of $2 \mathrm{~nm}$, and the diameter of a double helix of $2 \mathrm{~nm}[25,30]$. This yields a plate total surface area of $7000 \mathrm{~nm}^{2}$, and by assuming a $90 \%$ hexagonal packing efficiency, a maximum of 500 oligonucleotides per gold nanoplate are determined.

3.4. Laser-Induced Release of Doxorubicin. After loading the particles with DOX, the samples are exposed to laser light with $817 \mathrm{~nm}$ wavelength, a power density of $800 \mathrm{~mW} / \mathrm{cm}^{2}$, and duration of 5 minutes. The particles are then removed via centrifugation, and the amount of free DOX in the supernatants is quantified through fluorescence measurements. The samples show a consistent release pattern despite slight variations likely due to small amounts of particle aggregation. The average fluorescence reading after each lasering is shown in Figure 6 for GNP-Hairpin and Figure 7 for GNP-HairpinAS1411. As noted earlier, GNP-AS1411 is not evaluated due to the assumption that the loading of the DOX onto AS1411 is negligible. In addition, the fluorescence readings from the control GNP-oligoparticles without DOX that are lasered and processed in the same manner are shown. The percentage of DOX release that each laser application contributes to the 


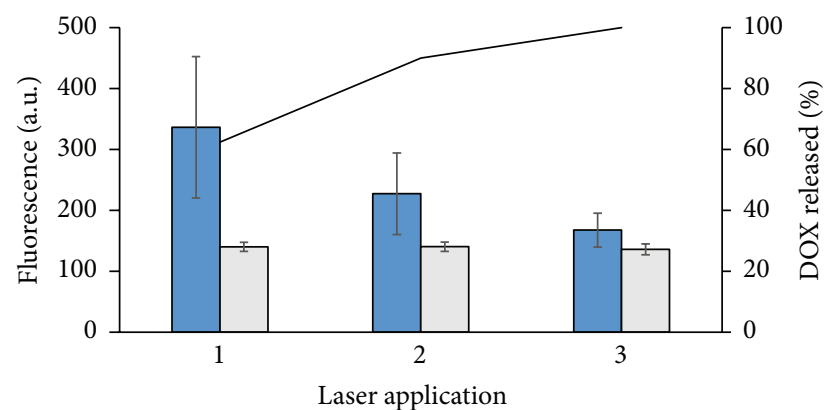

FIGURE 6: Fluorescence (a.u.) readings (left axis) of supernatants from lasered GNP-Hairpin samples loaded with DOX (blue bars) and control GNP-Hairpin samples without DOX (gray bars). The black line represents the percent of loaded DOX (right axis) released at each laser application. Laser light exposure is $817 \mathrm{~nm}$ wavelength at $800 \mathrm{~mW} / \mathrm{cm}^{2}$ for 5 minutes.

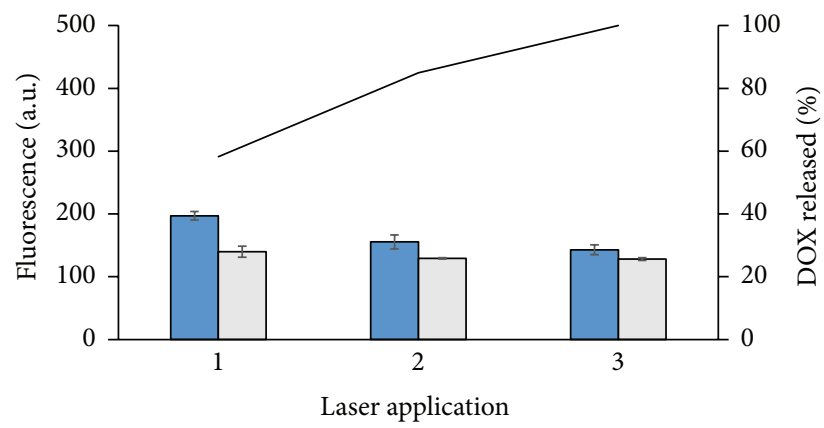

FIGURE 7: Fluorescence (a.u.) readings (left axis) of supernatants from lasered GNP-Hairpin-AS1411 samples loaded with DOX (blue bars) and control GNP-Hairpin-AS1411 samples without DOX (Gray bars). The black line represents the percent of loaded DOX (right axis) released at each laser application. Laser light exposure is $817 \mathrm{~nm}$ wavelength at $800 \mathrm{~mW} / \mathrm{cm}^{2}$ for 5 minutes.

total release is also represented in the figures. The average fluorescence readings for the GNP-Hairpin particles are 336.6, 227.4, and 167.6 FSU for the first, second, and third laser applications, respectively. Meanwhile, the control $\left(\mathrm{H}_{2} \mathrm{O}\right.$ only) registered 140.1, 140.3, and 136.2 FSU for the same laser application order. The fluorescence values for the GNPHairpin-AS1411 particles are lower at 197.1, 155.4, and 142.9 FSU. The analysis of variance for these results demonstrated that number of laser exposures, loaded or nonloaded, and GNP-Hairpin or GNP-Hairpin-AS1411 are all significantly different $(p<0.05)$ compared to controls.

These results indicate that there is a release of DOX due to the laser application with the first laser application releasing most of the DOX (58-62\%) from the particles. Analysis of variance shows a significant difference between the DOXloaded and control samples and also indicates that the effects of number of laser exposures and coating type are significant to the fluorescence measurement. This effectively serves as a proof of concept that the particles do behave as proposed to function as a vehicle for delivery and release of DOX.

The other measurement acquired during lasering is bulk solution temperature (Table 4). As anticipated, all solutions
TABLE 4: Maximum temperatures during laser application.

\begin{tabular}{lccc}
\hline \multirow{2}{*}{ Sample } & \multicolumn{3}{c}{ Maximum temperature $\left({ }^{\circ} \mathrm{C}\right)(\mathrm{std}$. dev. $)$} \\
& Laser 1 & Laser 2 & Laser 3 \\
\hline GNP-Hairpin-DOX & $50.7(6.2)$ & $46.7(8.6)$ & $43.3(8.6)$ \\
GNP-Hairpin & $47.3(4.0)$ & $43.2(4.2)$ & $40.3(4.5)$ \\
GNP-Hairpin-AS1411- & $47.2(9.5)$ & $45.8(9.7)$ & $44.0(8.3)$ \\
DOX & 27 & 26 & 26 \\
Water & & & \\
\hline
\end{tabular}

containing the functionalized GNPs did exceed the temperature of the samples containing water alone $(p<0.05)$, with a maximum and minimum temperature of $58^{\circ} \mathrm{C}$ and $37.5^{\circ} \mathrm{C}$, respectively. The overall average temperature for the DOX-loaded particles is $46.3 \pm 7.6^{\circ} \mathrm{C}$ and $43.4 \pm 3.7^{\circ} \mathrm{C}$ for particles with no DOX. Analysis of variance shows no significant difference in the maximum temperature for any factor differentiating samples, including DNA coating, DOX loading, or number of laser exposures.

These findings confirm that all samples are heated to nearly the same temperature. Although the slight variation in maximum temperature cannot be attributed to one particular factor, the variation likely comes from slight differences due to deviations during the manufacturing processes of the coated GNPs or bare particles themselves. Ultimately, the most important issue is that the gold particles are sufficiently heated to denature the hairpin structure to allow the DOX to be released. However, the bulk temperature that is reached by these samples does not rise above $60^{\circ} \mathrm{C}$, which is well below the melting temperature $\left(T_{M}\right)$ of the hairpin at $69.7^{\circ} \mathrm{C}$. Thus the local heating at the particle surface, induced by the SPR effect, is effectively dampened by the large volume of water into which the heat is dissipated, which results in the oligonucleotides conjugated to the particle surface likely experiencing greater thermal fluctuations compared to the bulk solutions. One study illustrates the bulk temperature induced by this local heating effect to be as high as $100^{\circ} \mathrm{C}$ [10]. This is also confirmed by the fact that, despite the bulk temperature of the solution being lower than $T_{\mathrm{M}}$ for the hairpin, significant DOX release is still observed, which implies that the hairpin is being denatured. The ability to effectively achieve hairpin denaturation and DOX release at bulk temperatures near $43^{\circ} \mathrm{C}$ is very useful in a practical sense, since it ensures the ability to achieve hyperthermic ablation of cancer cells without causing significant heatrelated damage to the surrounding tissues [31]. This method also provides a useful approach to correlating bulk temperature to the amount of DOX released over time, with temperature being an easily measurable metric.

\section{Cell Studies}

The photothermal DOX release system outlined above is subjected to preliminary testing in an in vitro cell culture model of lung cancer using A549 adenocarcinomic human epithelial cells and MDA-MB-231 breast cancer cells. Cells are exposed to the same GNP concentration of GNP-Hairpin or 

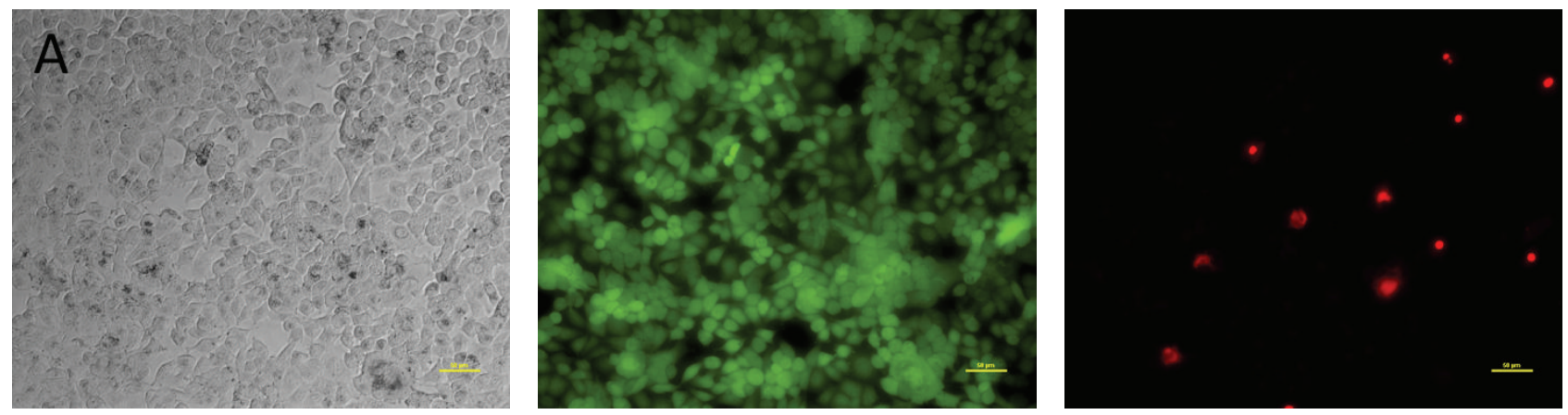

(a)
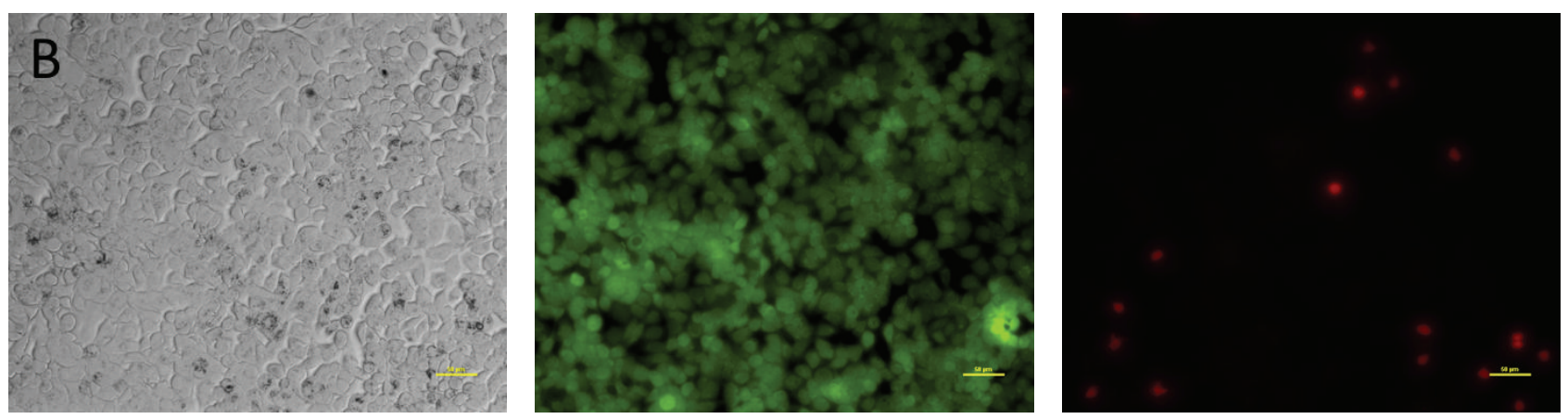

(b)
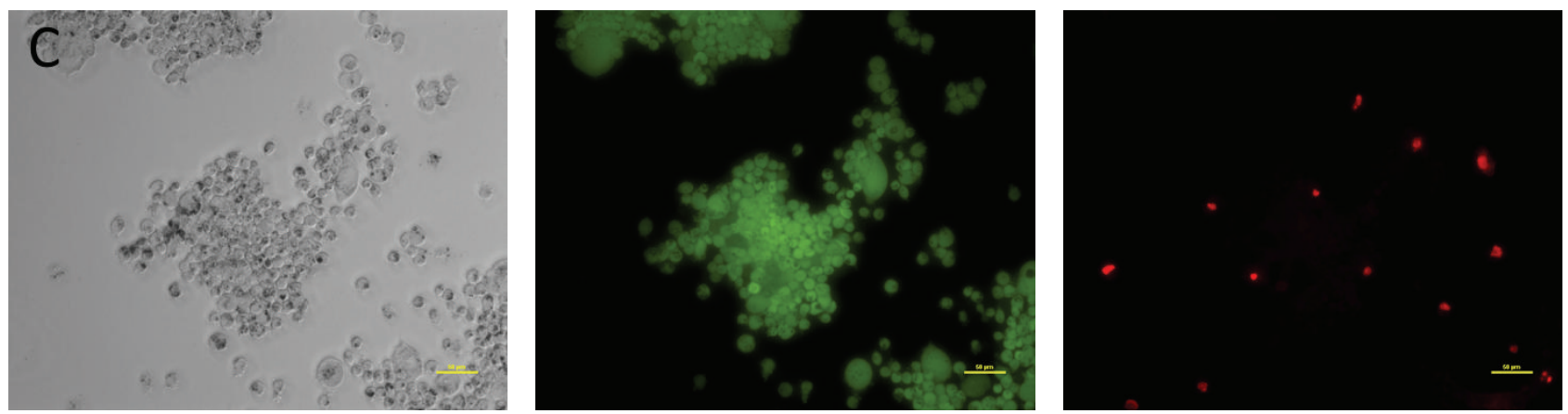

(c)
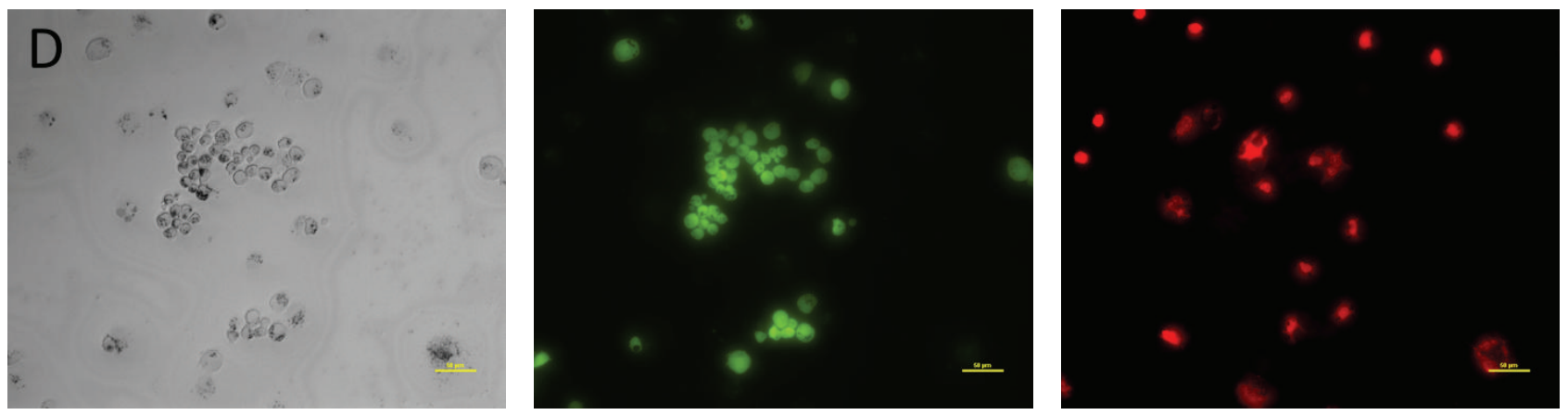

(d)

FIGURE 8: Bright field (left), fluorescence (live cells) (middle), and fluorescence (dead cells) (right) for A549 cells with (a) GNP-Hairpin (1 OD), no laser; (b) GNP-Hairpin (1 OD), laser; (c) GNP-Hairpin-DOX (1OD), no laser; and (d) GNP-Hairpin-DOX (1 OD) with laser treatment. 

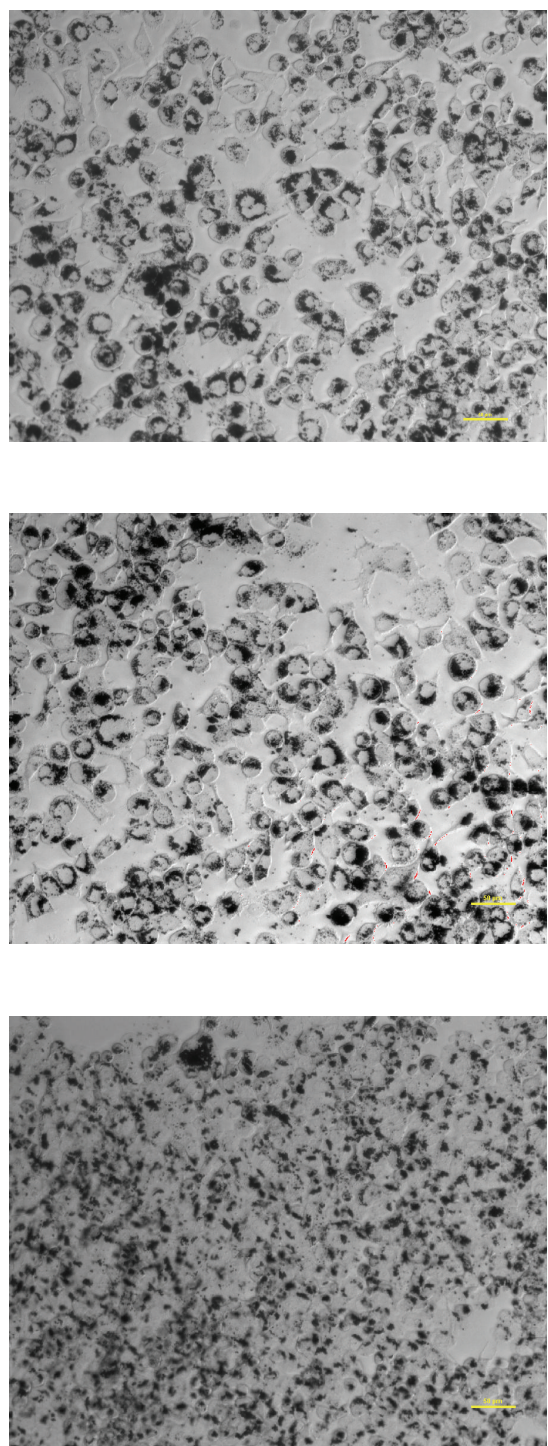

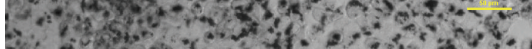
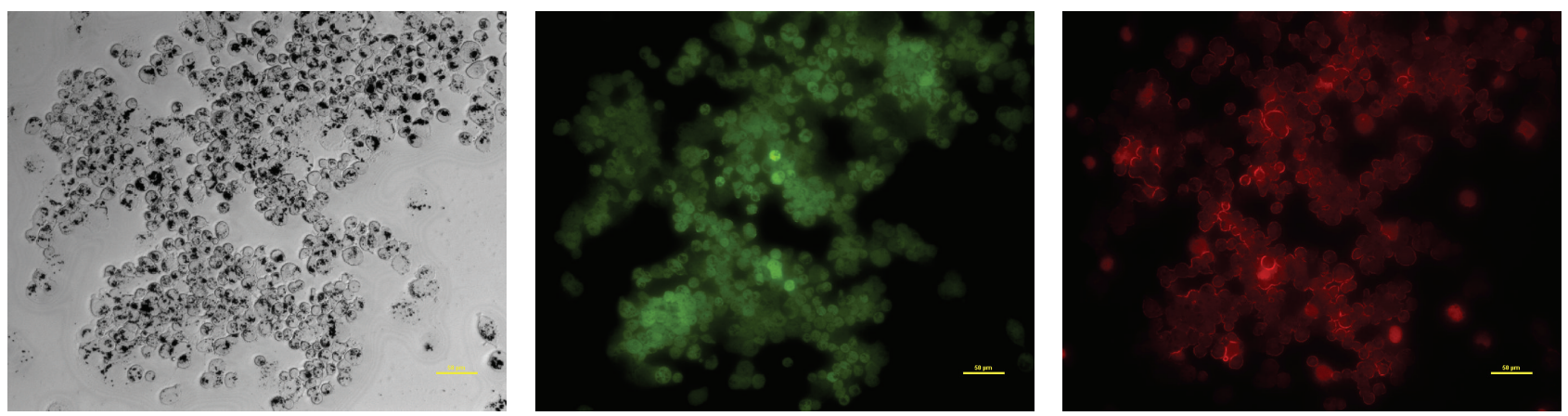

(d)

FIGURE 9: Bright field (left), fluorescence (live cells) (middle), and fluorescence (dead cells) (right) for MDA-MB-231 cells with (a) GNPHairpin (1 OD) no laser; (b) GNP-Hairpin (1 OD), laser; (c) GNP-Hairpin-DOX (1 OD), no laser; and (d) GNP-Hairpin-DOX (1 OD) with laser treatment. 
GNP-Hairpin-DOX nanoparticles used in the DOX release studies for $24 \mathrm{hrs}$ followed by repeated washings with PBS buffer before lasering the samples. Care is taken to reproduce the laser power and coverage area from the release studies. Laser exposure to A549 and MDA-MB-231 cells using the same exposure time and power as for the DOX release studies showed no ill effects to cell morphology and caused no significant cell death, Figures S2 and S3. Cell samples with and without DOX and with or without laser exposure are then subjected to a Live/Dead staining assay to visualize the number of cells killed by the DOX release process, Figures 8 and 9. Previous studies have shown that both laser exposure using these parameters and the bare gold nanoplates have no toxic effect on the cells $[10,11]$.

As demonstrated by the Live/Dead staining on both A549 and MDA-MB-231 cells, GNP-Hairpin has little toxic effect on the cells regardless of whether the laser is applied or not. The presence of the gold nanoplates is readily apparent in these cell cultures as dark black spots on the cells. Likewise, GNP-Hairpin-DOX has little effect on the cells in the absence of laser light; however, the DOX-loaded particles cause dramatically more cell death when the laser is applied. These results suggest that the cells are effectively shielded from the presence of DOX by the nanoplate delivery system in the absence of laser exposure since the DOX remains intercalated in the hairpin structures on the surface of the particles. In addition, laser-triggered release of the DOX from the DOX-loaded particles provides a sufficient amount of the chemotherapeutic agent to cause significant toxicity and cell death to both types of cancerous cells, as evidenced by fewer cells in the live cell image, and many more cells in the dead cell images for this set of experiments. It also appears that a significant portion of the cells are washed away in the lasered DOX samples, suggesting more cell death has occurred than is apparent in the images. These observations imply that the systemic administration of the DOX-loaded particles may avoid systemic toxicity due to the sequestration of the DOX within the particle framework. Targeted release of DOX through the judicious application of nIR energy can then pinpoint the spatial location of DOX release within the tissue. This method of triggered release allows the use of traditional IV drug infusion together with a minimally invasive release mechanism via tissue penetrating nIR light.

\section{Conclusion}

The work presented here has demonstrated the potential of gold nanoplates coated with DNA oligonucleotides to serve as a delivery vehicle for the controlled release of cancer drugs. GNPs with an SPR band in the nIR range are synthesized using the Diasynth method to preferentially separate nanoplates from nanospheres. The GNPs coated with two different DNA oligonucleotides result in particles with corresponding increases in particle size and more negative zeta potential. Laser-induced release of the doxorubicin from DNA is successfully demonstrated in bench top tests through fluorescence measurements.

Proof of concept DOX delivery and potential protection of healthy cells are also demonstrated through in vitro cell studies using breast and lung cancer cells as a model. In both cases, cells are significantly affected by the presence of DOX in the immediate environment only following laser-triggered release of the DOX from the nanoparticle conjugates. The promise of a selectively released chemotherapy drug with multiple molecules to treat cancer is a great improvement over traditional chemotherapy, greatly reducing the side effects while potentially increasing the efficacy. The ultimate potential of this research is the full production and use of these or similar particles for targeted cancer therapy in patients.

\section{Competing Interests}

Martin G. O’Toole, Mohammad Tariq Malik, and Paula J. Bates are coinventors on issued or pending patents related to nucleolin, AS1411, and AS1411-conjugated nanomaterials.

\section{Authors' Contributions}

Tyler Brann and Dhruvinkumar Patel contributed equally; Rajat Chauhan and Kurtis T. James contributed equally.

\section{References}

[1] D. A. Giljohann, D. S. Seferos, W. L. Daniel, M. D. Massich, P. C. Patel, and C. A. Mirkin, "Gold nanoparticles for biology and medicine," Angewandte Chemie-International Edition, vol. 49, no. 19, pp. 3280-3294, 2010.

[2] X. Zhang, "Gold nanoparticles: recent advances in the biomedical applications," Cell Biochemistry and Biophysics, vol. 72, no. 3, pp. 771-775, 2015.

[3] B. Pelaz, V. Grazu, A. Ibarra, C. Magen, P. del Pino, and J. M. de la Fuente, "Tailoring the synthesis and heating ability of gold nanoprisms for bioapplications," Langmuir, vol. 28, no. 24, pp. 8965-8970, 2012.

[4] H. R. Vutukuri, S. Badaire, D. A. M. De Winter, A. Imhof, and A. Van Blaaderen, "Directed self-assembly of micron-sized gold nanoplatelets into oriented flexible stacks with tunable interplate distance," Nano Letters, vol. 15, no. 8, pp. 5617-5623, 2015.

[5] R. D. Averitt, D. Sarkar, and N. J. Halas, "Plasmon resonance shifts of Au-coated Au2S nanoshells: insight into multicomponent nanoparticle growth," Physical Review Letters, vol. 78, no. 22, pp. 4217-4220, 1997.

[6] J. J. Diao and G. D. Chen, "Electromagnetic cavity resonant absorption of the gold nanoshell," Journal of Physics D: Applied Physics, vol. 34, no. 14, pp. L79-L82, 2001.

[7] A. M. Schwartzberg, C. D. Grant, T. van Buuren, and J. Z. Zhang, "Reduction of $\mathrm{HAuCl}_{4}$ by $\mathrm{Na}_{2} \mathrm{~S}$ revisited: the case for $\mathrm{Au}$ nanoparticle aggregates and against $\mathrm{Au}_{2} \mathrm{~S} / \mathrm{Au}$ core/shell particles," The Journal of Physical Chemistry C, vol. 111, no. 25, pp. 8892-8901, 2007.

[8] H. S. Zhou, I. Honma, H. Komiyama, and J. W. Haus, "Controlled synthesis and quantum-size effect in gold-coated nanoparticles," Physical Review B, vol. 50, no. 16, pp. 1205212056, 1994.

[9] R. Weissleder, "A clearer vision for in vivo imaging," Nature Biotechnology, vol. 19, no. 4, pp. 316-317, 2001. 
[10] A. M. Gobin, E. M. Watkins, E. Quevedo, V. L. Colvin, and J. L. West, "Near-infrared-resonant gold/gold sulfide nanoparticles as a photothermal cancer therapeutic agent," Small, vol. 6, no. 6, pp. 745-752, 2010.

[11] X. Sun, G. Zhang, R. S. Keynton, M. G. O’Toole, D. Patel, and A. M. Gobin, "Enhanced drug delivery via hyperthermal membrane disruption using targeted gold nanoparticles with PEGylated Protein-G as a cofactor," Nanomedicine: Nanotechnology, Biology, and Medicine, vol. 9, no. 8, pp. 1214-1222, 2013.

[12] D. Patel, K. T. James, M. O’Toole, G. Zhang, R. S. Keynton, and A. M. Gobin, "A high yield, one-pot dialysis-based process for self-assembly of near infrared absorbing gold nanoparticles," Journal of Colloid and Interface Science, vol. 441, pp. 10-16, 2015.

[13] K. T. James, M. G. O'Toole, D. N. Patel, G. Zhang, A. M. Gobin, and R. S. Keynton, "A high yield, controllable process for producing tunable near infrared-absorbing gold nanoplates," RSC Advances, vol. 5, no. 17, pp. 12498-12505, 2015.

[14] R. K. Delong, C. M. Reynolds, Y. Malcolm, A. Schaeffer, T. Severs, and A. Wanekaya, "Functionalized gold nanoparticles for the binding, stabilization, and delivery of therapeutic DNA, RNA, and other biological macromolecules," Nanotechnology, Science and Applications, vol. 3, no. 1, pp. 53-63, 2010.

[15] S. N. Barnaby, T. L. Sita, S. H. Petrosko, A. H. Stegh, and C. A. Mirkin, "Therapeutic applications of spherical nucleic acids," Cancer Treatment and Research, vol. 166, pp. 23-50, 2015.

[16] M. T. Malik, M. G. O'Toole, L. K. Casson et al., "AS1411conjugated gold nanospheres and their potential for breast cancer therapy," Oncotarget, vol. 6, no. 26, pp. 22270-22281, 2015.

[17] D. Agudelo, P. Bourassa, G. Bérubé, and H.-A. Tajmir-Riahi, "Intercalation of antitumor drug doxorubicin and its analogue by DNA duplex: structural features and biological implications," International Journal of Biological Macromolecules, vol. 66, pp. 144-150, 2014.

[18] P. J. Bates, D. A. Laber, D. M. Miller, S. D. Thomas, and J. O. Trent, "Discovery and development of the G-rich oligonucleotide AS1411 as a novel treatment for cancer," Experimental and Molecular Pathology, vol. 86, no. 3, pp. 151-164, 2009.

[19] R. A. Stahel and U. Zangemeister-Wittke, "Antisense oligonucleotides for cancer therapy-an overview," Lung Cancer, vol. 41, supplement 1, pp. S81-S88, 2003.

[20] E. M. Reyes-Reyes, Y. Teng, and P. J. Bates, “A new paradigm for aptamer therapeutic AS1411 action: uptake by macropinocytosis and its stimulation by a nucleolin-dependent mechanism," Cancer Research, vol. 70, no. 21, pp. 8617-8629, 2010.

[21] J. Song, Z. Li, Y. Cheng, and C. Liu, "Self-aggregation of oligonucleotide-functionalized gold nanoparticles and its applications for highly sensitive detection of DNA," Chemical Communications, vol. 46, no. 30, pp. 5548-5550, 2010.

[22] Y.-L. Luo, Y.-S. Shiao, and Y.-F. Huang, "Release of photoactivatable drugs from plasmonic nanoparticles for targeted cancer therapy," ACS Nano, vol. 5, no. 10, pp. 7796-7804, 2011.

[23] J. R. G. Navarro and M. H. V. Werts, "Resonant light scattering spectroscopy of gold, silver and gold-silver alloy nanoparticles and optical detection in microfluidic channels," Analyst, vol. 138, no. 2, pp. 583-592, 2013.

[24] Z. Guo, X. Fan, L. Liu et al., "Achieving high-purity colloidal gold nanoprisms and their application as biosensing platforms," Journal of Colloid and Interface Science, vol. 348, no. 1, pp. 29-36, 2010.
[25] M. Mandelkern, J. G. Elias, D. Eden, and D. M. Crothers, "The dimensions of DNA in solution," Journal of Molecular Biology, vol. 152, no. 1, pp. 153-161, 1981.

[26] X. Fan, Z. R. Guo, J. M. Hong, Y. Zhang, J. N. Zhang, and N. Gu, "Size-controlled growth of colloidal gold nanoplates and their high-purity acquisition," Nanotechnology, vol. 21, no. 10, Article ID 105602, 2010

[27] M. R. Jones, R. J. MacFarlane, B. Lee et al., "DNA-nanoparticle superlattices formed from anisotropic building blocks," Nature Materials, vol. 9, no. 11, pp. 913-917, 2010.

[28] M. R. Jones, R. J. Macfarlane, A. E. Prigodich, P. C. Patel, and C. A. Mirkin, "Nanoparticle shape anisotropy dictates the collective behavior of surface-bound ligands," Journal of the American Chemical Society, vol. 133, no. 46, pp. 18865-18869, 2011.

[29] G. D. Zhang, X. H. Sun, J. Jasinski, D. Patel, and A. M. Gobin, "Gold/chitosan nanocomposites with specific near infrared absorption for photothermal therapy applications," Journal of Nanomaterials, vol. 2012, Article ID 853416, 9 pages, 2012.

[30] C.-J. Lee, J.-S. Kim, M.-S. Lee, K.-P. Lee, and M.-S. Lee, “The study of doxorubicin and its complex with DNA by SERS and UV-resonance Raman spectroscopy," Bulletin of the Korean Chemical Society, vol. 25, no. 8, pp. 1211-1216, 2004.

[31] T. Kobayashi, "Cancer hyperthermia using magnetic nanoparticles," Biotechnology Journal, vol. 6, no. 11, pp. 1342-1347, 2011. 

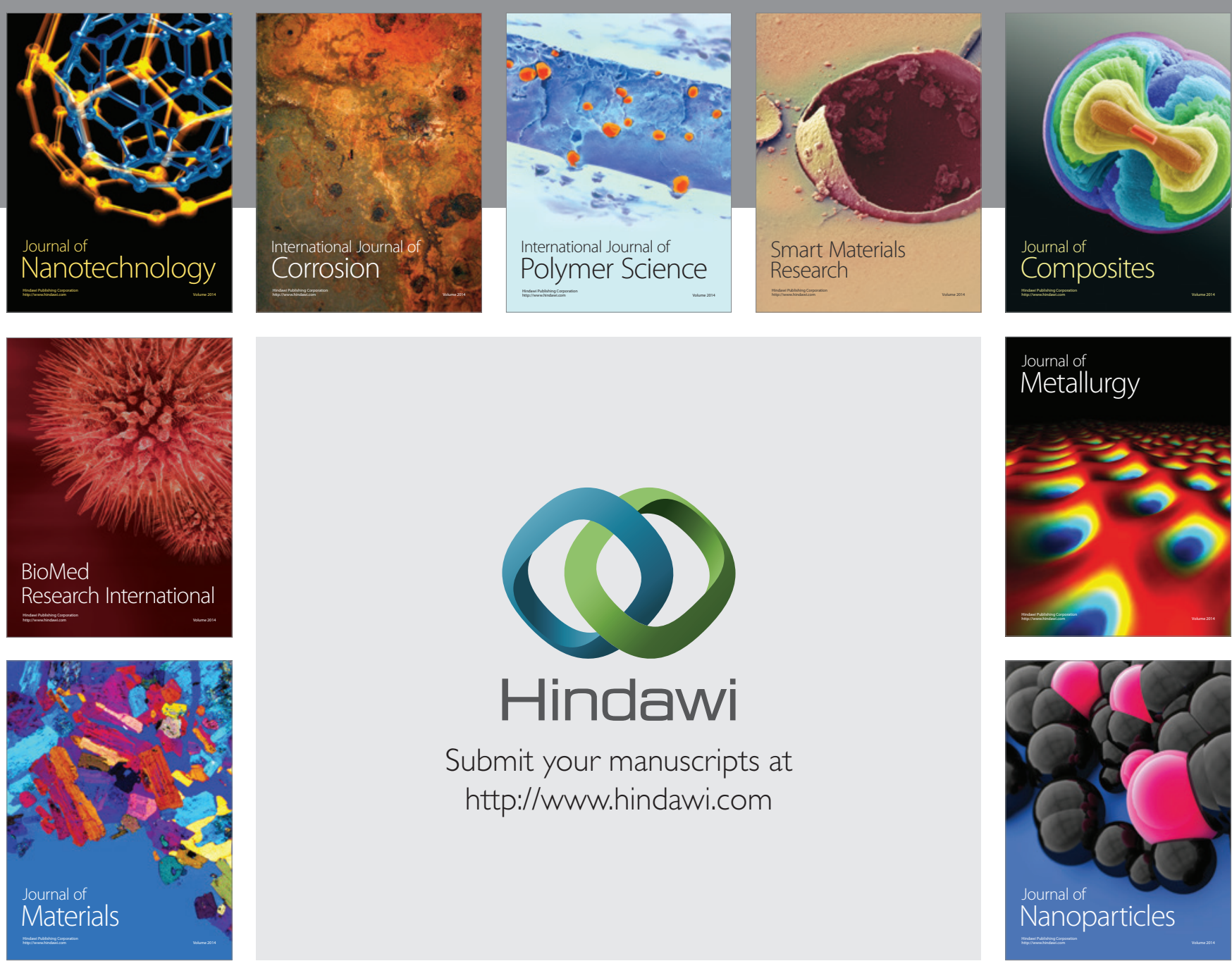

\section{Hindawi}

Submit your manuscripts at

http://www.hindawi.com

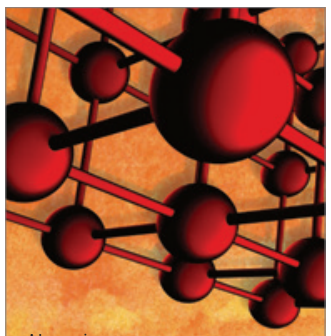

Materials Science and Engineering
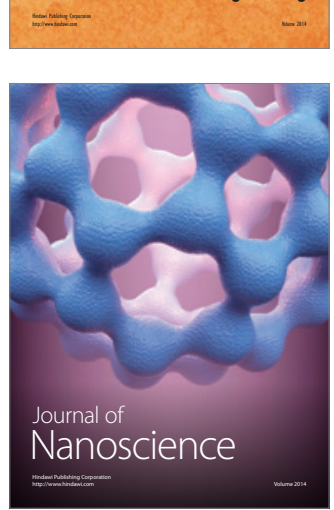
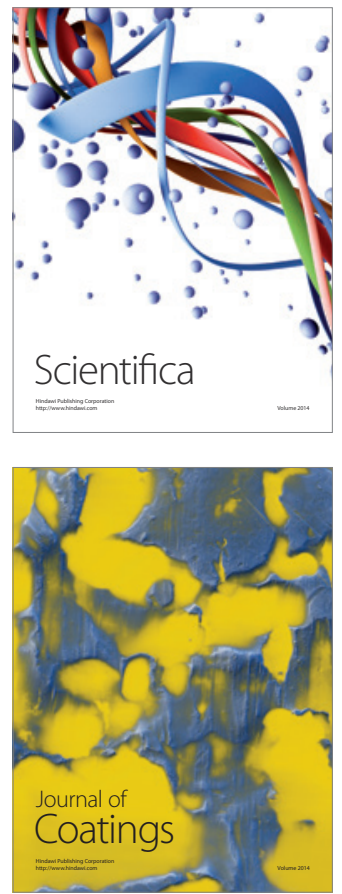
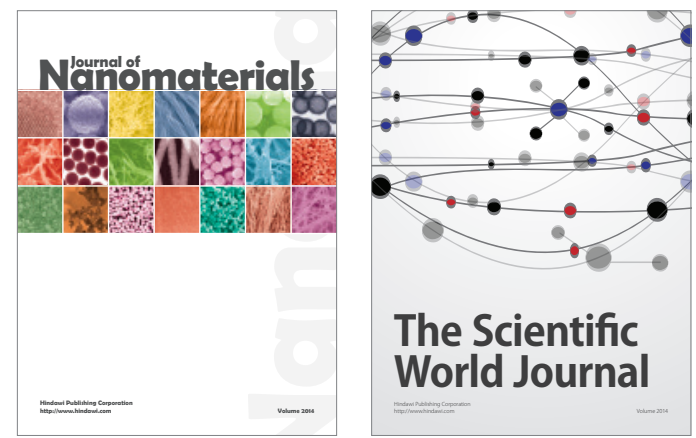

The Scientific World Journal
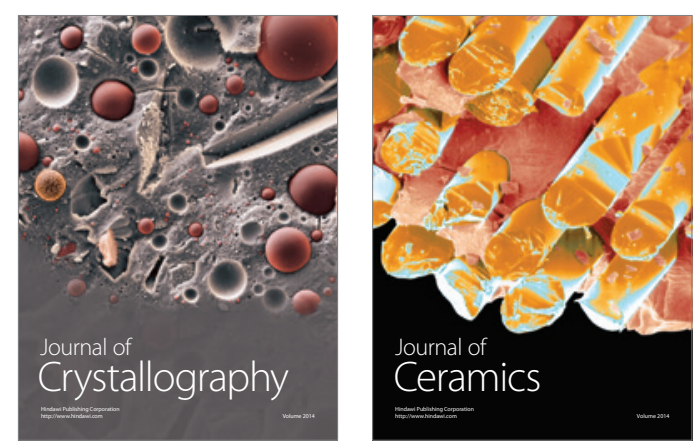
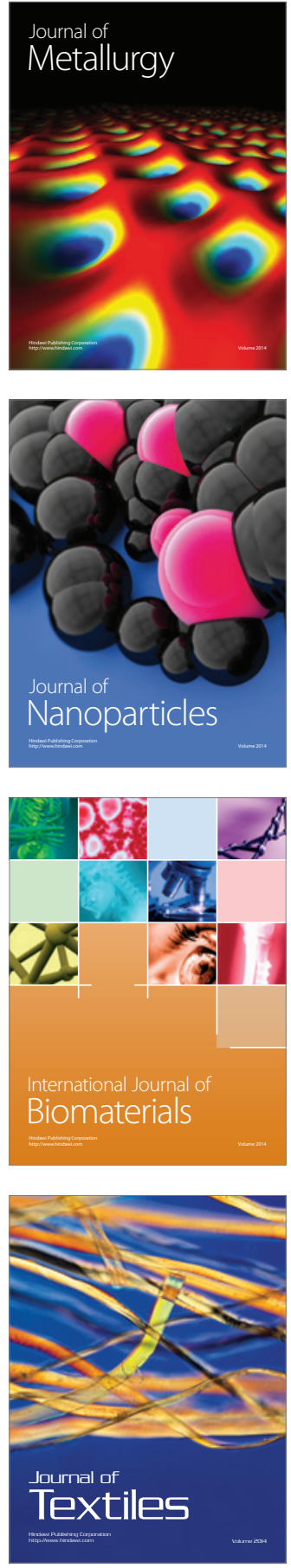